\title{
The use of digital photographs for the diagnosis of hand osteoarthritis: the AGES-Reykjavik study
}

\author{
Helgi Jonsson ${ }^{1 *}$, Gudrun P Helgadottir ${ }^{2}$, Thor Aspelund ${ }^{3}$, Johanna E Sverrisdottir ${ }^{4}$, Gudny Eiriksdottir ${ }^{4}$, \\ Sigurdur Sigurdsson ${ }^{4}$, Gudmundur J Eliasson ${ }^{5}$, Asbjorn Jonsson ${ }^{1}$, Thorvaldur Ingvarsson 6 , Tamara B Harris ${ }^{7}$, \\ Lenore Launer ${ }^{7}$ and Vilmundur Gudnason ${ }^{3}$
}

\begin{abstract}
Background: The objective of the study was to standardize a method using digital photographs to diagnose and grade hand osteoarthritis ( $\mathrm{HOA}$ ), to compare it with radiographs and clinical examination with regard to prevalence and relation to symptoms, and finally to construct a simple shortened version suitable for use in very large studies, where a global estimate may be preferable.
\end{abstract}

Methods: High quality photographs with standard distance and hand positioning were analysed for the presence of HOA and subsequently compared with standard radiographs and clinical examination in 381 random participants in the AGES-Reykjavik Study, a large population study. The mean age of the participants was 76 years.

Results: Using the photographic method, the most commonly affected joints were the second DIP joints followed by the third DIP joints and second and third PIP joints. Both interobserver $(I C C=0.83)$ and intraobserver reading agreements (ICC $=0.89$ ) were acceptable. On comparison with radiography and clinical examination, aggregate scores were significantly correlated $\left(R_{s} 0.35-0.69\right)$, more so in females $\left(R_{s} 0.53-0.72\right)$ than males. Hand pain in males showed very little association with $\mathrm{HOA}$ findings by the three methods but all methods showed a comparable moderate association with hand pain in females. The performance of photography in predicting pain on most days for at least a month in females was comparable to that of radiography and clinical examination (AUC $0.63 p=$ 0.004). Analysis of intermittent pain yielded similar results for in the DIP and PIP joints (OR 3.2-3.3, $p<0.01$ ), but for the CMC1 joints, both radiography (OR 9.0, $p<0.0001$ ), and clinical examination (OR 9.8, $p<0.0001$ ), had higher predictive odds ratios for pain than photography (OR 3.6, $p<0.0001)$., A shortened, rapidly performed form of reading photographs also showed a high degree of correlation with the other methods $\left(R_{s} 0.56-0.82\right)$.

Conclusion: High quality hand photographs can be used to diagnose and grade hand osteoarthritis. The method has the advantage of being inexpensive and easy to perform. By using a slightly simplified method of reading, it appears to be highly suitable for use in large studies.

Keywords: Hand ostearthritis, Generalized osteoarthritis, Epidemiology, Imaging, Photography

\section{Background}

Hand osteoarthritis (HOA) is an important cause of pain and disability in the middle aged and elderly [1-3]. In addition to symptoms directly related to the hand itself, it is also related to osteoarthritis at other sites and there is evidence that the presence of HOA increases the propensity for the development and progression of

\footnotetext{
* Correspondence: helgi@hi.is

'Landspitalinn University Hospital, University of Iceland, IS-108 Fossvogur, Reykjavik, ICELAND

Full list of author information is available at the end of the article
}

both knee and hip osteoarthritis (OA) [4]. This relationship, usually referred to as "generalized osteoarthritis" (GOA) has proved hard to define, despite some serious efforts $[5,6]$. The reasons are complex and among them are gender and age related differences and problems with measures of the disease activity and progress. Imaging is particularly problematic, radiography has been considered the gold standard for diagnosis and monitoring of HOA, but the method is basically a delayed reflection of damage and repair caused by OA, showing only moderate association with symptoms and giving
C Biomed Central 
little information about prognosis $[7,8]$. Other imaging modalities such as scintigraphy, ultrasound and magnetic resonance imaging (MRI) have the advantage of being more dynamic and thus give a better indication of disease activity in the various tissues of the joints. All of these methods may be useful, but for various reasons including cost, availability and interpretation, none of them is likely to replace radiography in larger studies. The use of hand photographs as a screening method for HOA has been investigated in a few studies but found to be less sensitive than radiography [9-11].

The pathogenesis of osteoarthritis is still obscure and theories are evolving. Previously, OA was considered a degenerative disease, and simply an inevitable part of ageing. Now, however, OA is increasingly viewed as a dynamic process, one that is metabolically active, with the process of the disease involving both destruction and repair that may be triggered by a variety of biochemical as well as mechanical insults [12].

Members of our group have considerable experience in using different diagnostic methods for HOA including clinical examination [13], scintigraphy and MRI, both cross-sectional and longitudinal [14-16] and radiography with both the Kellgren-Lawrence and the VerbruggenVeys scoring systems $[17,18]$. Different subsets have also been studied including hypermobile subjects and individuals with known genetic mutations $[19,20]$. Based on this experience, we think it may be time to consider HOA as trait or disease burden which is not well measured by any of the current methods and that larger studies involving investigations of other organ systems may be necessary for further understanding of the systemic factors involved in osteoarthritis. There is evidence that HOA is a systemic disorder interacting with other organ systems and sharing pathophysiological pathways with other conditions such as atherosclerosis [21,22]. This association was discovered only by linking photographic HOA information to the extensive database of information gathered in the AGES-Reykjavik Study [21].

Hand photography is a simple and inexpensive imaging method involving no ionizing radiation or discomfort. This project of using photographs to diagnose and grade $\mathrm{HOA}$ is based on the belief that by standardizing the taking and the reading of the photographs, we would acquire a method that would be very suitable for use in large studies, allowing a wide variety of association studies. This article describes the process of establishing this method in four main steps: (1) To develop a standardized reproducible grading system for the diagnosis of hand osteoarthritis from high quality hand photographs. (2) To compare the photographic scoring system with the two main diagnostic methods currently used; radiography and clinical examination. (3) To analyze the relationship between the three methods and hand pain, the main symptom of hand osteoarthritis (4). To construct a shortened version of the photographic method as a diagnostic tool suitable for very large samples, where a simple global assessment of HOA may be preferable.

\section{Methods}

The Age, Gene/Environment Susceptibility-Reykjavik Study (AGES-Reykjavik) study is a population based study of approximately 5700 elderly individuals from the 40 year long Reykjavik study. They were aged between 66 and 96 and randomly recruited between 2002 and 2005. Details of the investigations are described in the study's baseline article [23]. The participants had extensive laboratory and imaging investigations including high quality hand photographs.

\section{Hand osteoarthritis study sample}

Preliminary power analysis based on the expected prevalence of hand OA indicated that a sample of approximately 400 individuals would be suitable for comparison of photography and radiography for the diagnosis of hand OA. Between the months of February and June of 2005, 389 random AGES-Reykjavik Study subjects agreed to participate. Participation involved having a detailed clinical examination of the hands and a hand radiograph taken. Other diseases affecting visual assessment or the development of hand OA were recorded (e. g. inflammatory arthropathies, Dupuytren's contracture, neuropathies, post-traumatic) and those subjects disqualified. Thus there were 381 eligible participants, 159 males and 222 females.

\section{Hand pain documentation}

Participants were questioned about hand symptoms with the following questions: 1) Have you ever had pain lasting at least one month in the joints of your hands or wrist? (The ACR criterion for diagnosis of hand OA). 2) In the past 12 months have you had pain lasting at least one month in the joints of your hands? 3a) Do you sometimes have pain in the joints of your hands? 3b) If yes, participants were asked to fill out a diagram showing in which joint the pain was located.

\section{Radiographic procedure}

Standard radiographs were taken of both hands. All radiographs were examined by two experienced radiologists (GJE and AJ). Interreliability was found to be excellent $(\mathrm{ICC}=0.87)$. Consensus scores were reached at a second sitting. The degree of radiographic OA in individual joints was graded using the Kellgren-Lawrence scoring system [17] $(0=$ absence; $1=$ doubtful; $2=$ mild; 3 = moderate; $4=$ severe). Grade 2 or higher was considered a definite sign of radiographic OA. 


\section{Clinical hand examination}

All subjects were examined by an experienced clinical examiner $(\mathrm{HJ})$. Individual hand joints were scored on the basis of structural changes, i.e. bony enlargement and deformity but not pain, on a $0-3$ scale as follows: 0 $=$ no evidence of OA, 1 = suspected but not definite OA, 2 = definite moderate OA, 3 = severe OA. Grade 2 or higher was considered a definite sign of clinically diagnosed OA.

\section{Photographic reading procedure}

All photographs were taken with a Fuji Finepix 6800 zoom camera with images taken at $2800 \times 2200$ pixels. The camera was mounted on a tripod with a fixed distance to a black velvet board with markers for thumb positioning. The quality of the digital images and correct thumb positioning is important in order for the readers to be able to visually assess the degree of enlargement and deformity.

A photographic scoring system was developed. Initially, the readers $(\mathrm{HJ}, \mathrm{GPH})$ examined a few photographs at a time recording a number of variables that were suspected to be related to hand osteoarthritis in each joint. Each individual hand joint was graded separately. Subsequently the observers results were compared with each other and with hand radiographs. After a number of sessions, the variables most likely to be associated with clinical and radiographic hand OA were determined. Several factors were found to be of importance, such as hard tissue enlargement, visible soft tissue swelling, position and deformity.

The distal interphalangeal (DIP) and the proximal interphalangeal (PIP) joints were scored on a 0-3 scale as follows: $0=$ no evidence of OA, $1=$ suspected but not definite $\mathrm{OA}, 2$ = definite moderate $\mathrm{OA}, 3$ = severe OA.

For the DIP joints, the deformity of a joint without hard tissue enlargement did not justify the diagnosis of hand OA on its own but when deformity was severe (> $30^{\circ}$ ), the recorded score was raised by one (1) unit (to the maximum score of 3 ).

Reference photographs for the grading of DIP and PIP joints are shown in Figures 1 and 2. For uniformity of presentation the right second DIP and third PIP joints are shown.

For assessment of OA of the first carpometacarpal (CMC1) joints, a slightly different approach was needed. Two different findings, enlargement of the joint and abnormal positioning, were related to OA in that joint. Abnormal positioning reflects palmar migration of the base of the first metacarpal bone and is reflected on photography by a number of factors, including

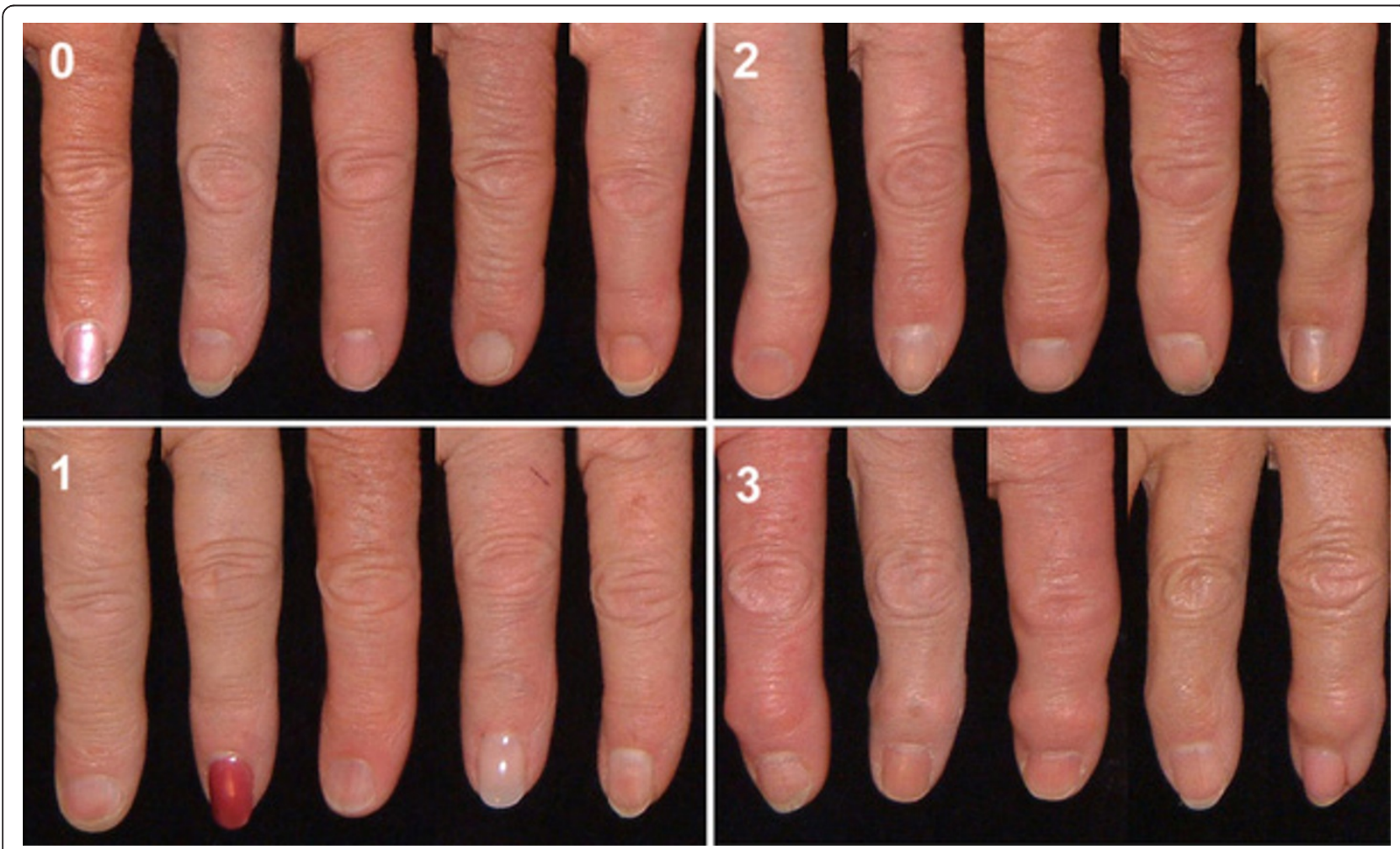

Figure 1 Reference photographs showing the grading of osteoarthritis of the right second DIP joint. The joint is given a score (0-3) for hard tissue enlargement and deformity of the joint. 


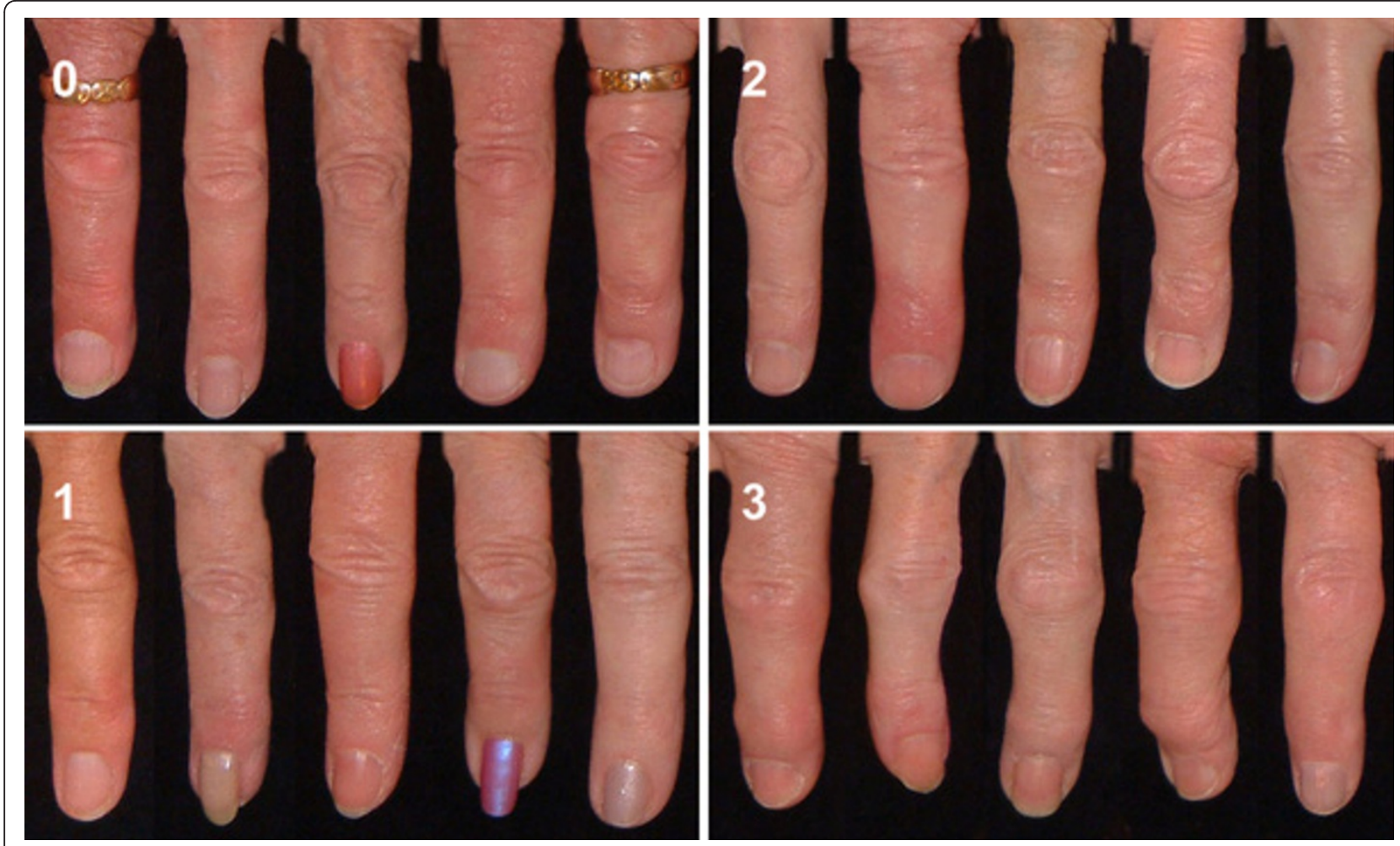

Figure 2 Reference photographs showing the grading of osteoarthritis of the right third PIP joint. The joint is given a score (0-3) for hard tissue enlargement and deformity of the joint.

disappearance of the normal configuration of the $\mathrm{CMC1}$ joint, medial rotation of the thumb showing increased folding of the skin over the first metacarpal joint (MCP1) and sometimes hyperextension of that joint.

Both enlargement and position were scored on a $0-3$ scale, $(0=$ no evidence of $\mathrm{OA}, 1=$ suspected but not definite OA, 2 = definite moderate OA, 3 = severe OA.) and subsequently added, giving a score of 0-6 which was translated into a $0-3$ score as follows: $(0=$ Normal joint, $1=$ Doubtful OA, 2-3 = Definite OA and $4+=$ Severe OA). Reference photos for the CMC1 joints are shown in Figure 3.

The reference photographs were subsequently used as assistive tools in the reading of all photographs. Interreader agreement measured by ICC was good (average 0.83 ) and intrareader agreement (50 photographs reread at 4 weeks intervals, GPH) was excellent (ICC 0.89) (Table 1). Finally the readers re-examined all discordant readings and decided upon a consensus score.

\section{Statistics}

All statistical analyses were carried out with SPSS (v. 16.0) and SAS/STAT (version 9.2). For estimates of interobserver and intraobserver reliability and agreement for assessment of individual joints Kappa (on/off) (where grade 2 was used as cut-off point) and Average Measure Intraclass Correlation Coefficient (ICC) were used.
In order to compare severity measures of OA between the three methods photography, radiography and clinical examination we used an aggregate score from 10 joints (The second and third DIP joints, second and third PIP joints and the CMC1 joint on either side). The same score was also used to investigate the relationship with reported pain

Due to prevalence differences between the genders, prevalence data were calculated for males and females separately. Spearman rank correlation coefficient $\left(R_{s}\right)$ was used to assess correlations. The associations between reported pain and diagnosis of osteoarthritis by photographs, clinical examination, and radiography were compared with a logistic regression model. We assessed the odds ratios (ORs) with 95\% confidence intervals for the DIP, PIP, and CMC1 joint groups separately, adjusting for age, BMI, smokingstatus and education level.

A receiver operating characteristic (ROC) curve analysis was performed for accuracy of the three methods in predicting pain.

\section{Results}

The baseline characteristics of the study participants are shown in Table 2. The joint for joint prevalence of photographic osteoarthritis in the interphalangeal joints is shown in Tables 3, 4 and 5. Distal interphalangeal 

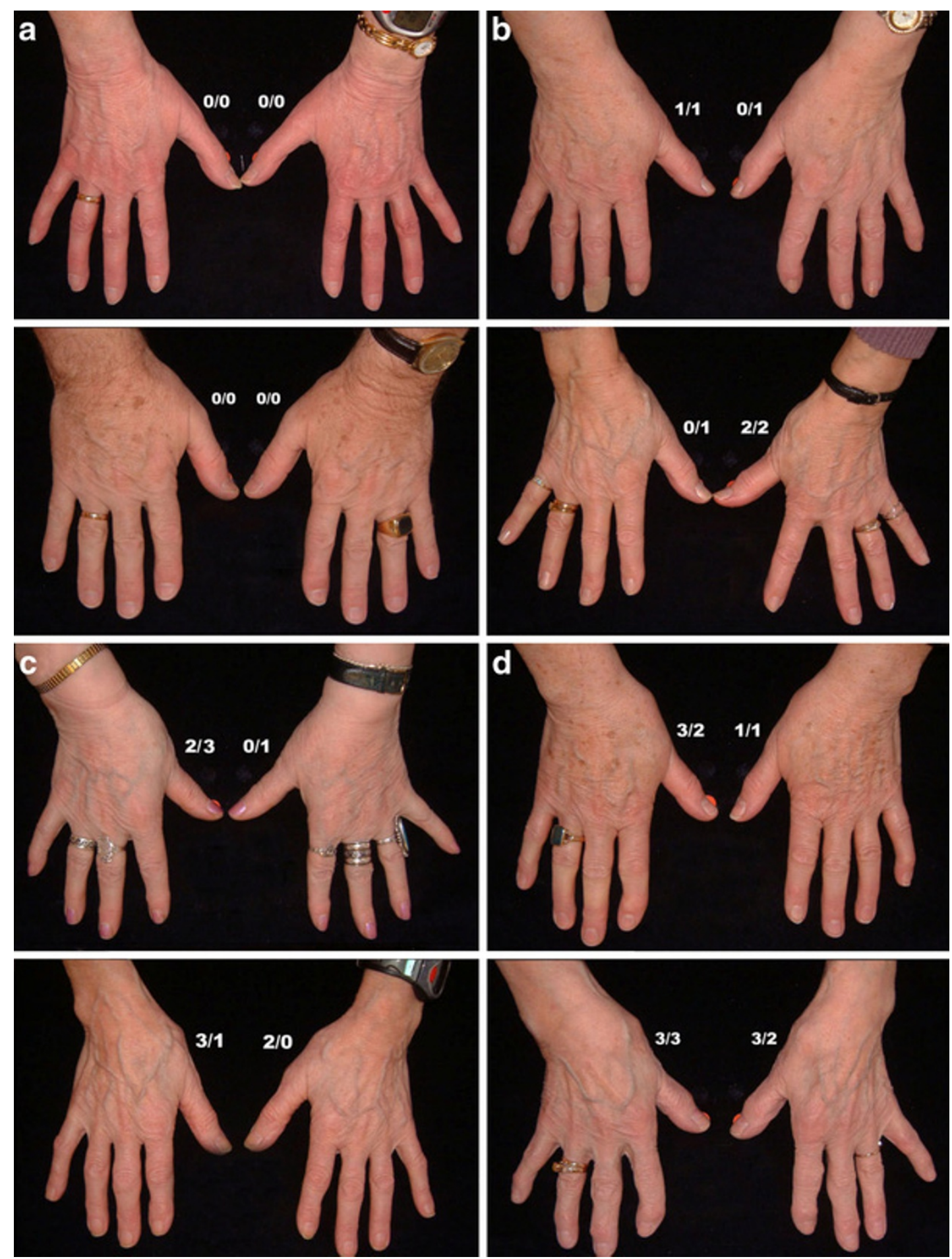

Figure 3 Reference photographs showing the grading of osteoarthritis of the CMC1 joints. The number on the left is the score for enlargement of the joint (0-3) and the number on the right represents position/subluxation of the thumb (0-3). a) Healthy CMC1 joints. b, c, d) Increasing osteoarthritis of the CMC1 joints. 
Table 1 Inter- and intraobserver agreement for photograph reading measured by Kappa and Average Measure Intraclass Coefficient (ICC)

\begin{tabular}{lcccc}
\hline & Joint & $\begin{array}{c}\text { Interobserver } \\
\text { kappa }\end{array}$ & $\begin{array}{c}\text { Interobserver } \\
\text { ICC }\end{array}$ & $\begin{array}{c}\text { Intraobserver } \\
\text { ICC }\end{array}$ \\
\hline Left & DIP5 & 0.83 & 0.85 & 0.90 \\
& DIP4 & 0.87 & 0.83 & 0.91 \\
& DIP3 & 0.85 & 0.84 & 0.93 \\
& DIP2 & 0.80 & 0.84 & 0.95 \\
& PIP5 & 0.92 & 0.79 & 0.81 \\
& PIP4 & 0.94 & 0.78 & 0.90 \\
& PIP3 & 0.86 & 0.86 & 0.92 \\
Right & PIP2 & 0.84 & 0.81 & 0.81 \\
& CMC1 & 0.87 & 0.88 & 0.91 \\
& DIP5 & 0.82 & 0.84 & 0.87 \\
& DIP4 & 0.88 & 0.80 & 0.94 \\
& DIP3 & 0.88 & 0.85 & 0.93 \\
& DIP2 & 0.79 & 0.78 & 0.95 \\
& PIP5 & 0.95 & 0.83 & 0.88 \\
Average for all 18 joints & 0.87 & 0.80 & 0.89 \\
& PIP4 & 0.97 & 0.83 & 0.89 \\
PIP3 & 0.89 & 0.87 & 0.84 \\
& PIP2 & 0.84 & 0.81 & 0.95 \\
& CMC1 & 0.89 & 0.89 &
\end{tabular}

joint (DIP) OA was more common than proximal interphalangeal joint (PIP) OA in both genders and definite and severe OA was more prevalent in females. There was a slight right side predominance of OA. The most prevalent DIP joint was the right DIP2 joint and for the PIP joints it was the right PIP3 joint.

The prevalence of $\mathrm{OA}$ in the $\mathrm{CMC} 1$ joints is shown in Table 6. For this joint we found more distinct gender differences. Severe OA was only seen in females and the prevalence of definite or severe $\mathrm{OA}$ in the right $\mathrm{CMC1}$ join in females was $21.6 \%$ vs $5.7 \%$ in males. There was also a tendency towards more involvement on the right side.

\section{Comparison of photography with radiography and clinical examination}

According to the photographic method, $60.4 \%$ of males had at least one affected hand joint, $85.5 \%$ had
Table 3 Consensus photographic scores for the DIP and PIP joints for all subjects

\begin{tabular}{|c|c|c|c|c|c|c|}
\hline & \multirow[b]{2}{*}{ Joint } & \multicolumn{4}{|c|}{ Grade } & \\
\hline & & 0 & 1 & 2 & 3 & \\
\hline & & $n$ & $n$ & $n$ & $n$ & Total $n$ \\
\hline \multicolumn{7}{|l|}{ Right hand } \\
\hline & DIP5 & 163 & 143 & 66 & 7 & 379 \\
\hline & DIP4 & 231 & 109 & 38 & 2 & 380 \\
\hline & DIP3 & 201 & 113 & 50 & 12 & 376 \\
\hline & DIP2 & 99 & 154 & 100 & 22 & 375 \\
\hline & PIP5 & 281 & 67 & 30 & 0 & 378 \\
\hline & PIP4 & 320 & 47 & 11 & 2 & 380 \\
\hline & PIP3 & 214 & 103 & 54 & 8 & 379 \\
\hline & PIP2 & 192 & 140 & 43 & 2 & 377 \\
\hline \multicolumn{7}{|l|}{ Left hand } \\
\hline & DIP5 & 180 & 137 & 55 & 7 & 379 \\
\hline & DIP4 & 232 & 118 & 23 & 4 & 377 \\
\hline & DIP3 & 183 & 136 & 53 & 6 & 378 \\
\hline & DIP2 & 116 & 169 & 85 & 10 & 380 \\
\hline & PIP5 & 303 & 52 & 26 & 0 & 381 \\
\hline & PIP4 & 349 & 22 & 5 & 3 & 379 \\
\hline & PIP3 & 255 & 91 & 29 & 5 & 380 \\
\hline & PIP2 & 213 & 144 & 21 & 2 & 380 \\
\hline
\end{tabular}

radiographic $\mathrm{OA}$ and $74.2 \%$ clinically diagnosed $\mathrm{OA}$ in at least one of the 18 hand joints. In females, the percentages were $66.2 \%, 93.7 \%$ and $82.4 \%$, respectively.

We searched for confounding factors affecting the prevalence of HOA by the three methods. Despite a slight trend for increasing prevalence of HOA with age, we found no significant association with age for any of the methods. Weight (and BMI), however showed a significant negative association with HOA scores by the photographic method $(p<0.001)$ but not with the other two methods suggesting that the prevalence of HOA in overweight subjects may be underestimated on photographic assessment. Other possible confounding factors, such as smoking history and education were not associated with HOA scores by any of the methods.

The prevalences of Hand OA in the DIP, PIP and $\mathrm{CMC} 1$ joints by the three different methods is shown in Table 7. The cut-off points were chosen as those

Table 2 Baseline characteristics of the study participants

\begin{tabular}{lccc}
\hline & All participants $(\mathbf{n}=\mathbf{3 8 1})$ & Males(n = 159) & Females(n = 222) \\
\hline Age (SD) & $76(5.0)$ & $76(4.4)$ & $76(5.3)$ \\
Heigth(SD) & $167.2(9.2)$ & $175.6(6.4)$ & $161.2(5.5)$ \\
Weight(SD) & $76.6(14.0)$ & $83.7(13.0)$ & $71.5(12.4)$ \\
Body Mass Index (BMI) & $27.4(4.3)$ & $27.1(3.9)$ & $27.5(4.6)$ \\
Hand joint pain 1 month ever (ACR criterion)\% & 20.2 & 10.7 & 27.0 \\
Hand pain lasting 1 month past year\% & 13.1 & 4.4 & 19.4 \\
Hand pain sometimes\% & 28.3 & 10.1 & 41.4 \\
\hline
\end{tabular}


Table 4 Consensus photographic score for the DIP and PIP joints for males

\begin{tabular}{|c|c|c|c|c|c|c|}
\hline & & & & & & \\
\hline & Joint & 0 & 1 & 2 & 3 & \\
\hline & & $n$ & $n$ & $n$ & $n$ & Total $n$ \\
\hline Right hand & & & & & & \\
\hline & DIP5 & 73 & 59 & 25 & 1 & 158 \\
\hline & DIP4 & 103 & 42 & 13 & 0 & 158 \\
\hline & DIP3 & 91 & 45 & 17 & 2 & 155 \\
\hline & DIP2 & 43 & 78 & 37 & 0 & 158 \\
\hline & PIP5 & 116 & 30 & 11 & 0 & 157 \\
\hline & PIP4 & 129 & 22 & 7 & 0 & 158 \\
\hline & PIP3 & 81 & 46 & 28 & 2 & 157 \\
\hline & PIP2 & 72 & 60 & 24 & 0 & 156 \\
\hline Left hand & & & & & & \\
\hline & DIP5 & 73 & 61 & 24 & 0 & 158 \\
\hline & DIP4 & 99 & 49 & 7 & 0 & 155 \\
\hline & DIP3 & 83 & 57 & 16 & 0 & 156 \\
\hline & DIP2 & 43 & 78 & 37 & 0 & 158 \\
\hline & PIP5 & 121 & 21 & 17 & 0 & 159 \\
\hline & PIP4 & 145 & 11 & 1 & 0 & 157 \\
\hline & PIP3 & 96 & 43 & 17 & 2 & 158 \\
\hline & PIP2 & 83 & 64 & 11 & 0 & 158 \\
\hline
\end{tabular}

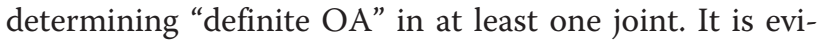
dent that the sensitivities of the methods vary, with radiography being the most sensitive of the three for all joint groups. Compared with the other two methods,

Table 5 Consensus photographic score for the DIP and PIP joints for females

\begin{tabular}{|c|c|c|c|c|c|c|}
\hline & \multirow[b]{2}{*}{ Joint } & \multicolumn{4}{|c|}{ Grade } & \\
\hline & & 0 & 1 & 2 & 3 & \\
\hline & & $n$ & $n$ & $n$ & $n$ & Total $n$ \\
\hline \multicolumn{7}{|l|}{ Right hand } \\
\hline & DIP5 & 90 & 84 & 41 & 6 & 221 \\
\hline & DIP4 & 128 & 67 & 25 & 2 & 222 \\
\hline & DIP3 & 110 & 68 & 33 & 10 & 221 \\
\hline & DIP2 & 46 & 92 & 65 & 17 & 220 \\
\hline & PIP5 & 165 & 37 & 19 & 0 & 221 \\
\hline & PIP4 & 191 & 25 & 4 & 2 & 222 \\
\hline & PIP3 & 133 & 57 & 26 & 6 & 222 \\
\hline & PIP2 & 120 & 80 & 19 & 2 & 221 \\
\hline \multicolumn{7}{|l|}{ Left hand } \\
\hline & DIP5 & 107 & 76 & 31 & 7 & 221 \\
\hline & DIP4 & 133 & 69 & 16 & 4 & 222 \\
\hline & DIP3 & 100 & 79 & 37 & 6 & 222 \\
\hline & DIP2 & 73 & 91 & 48 & 10 & 222 \\
\hline & PIP5 & 182 & 31 & 9 & 0 & 222 \\
\hline & PIP4 & 204 & 11 & 4 & 3 & 222 \\
\hline & PIP3 & 159 & 48 & 12 & 3 & 222 \\
\hline & PIP2 & 130 & 80 & 10 & 2 & 222 \\
\hline
\end{tabular}

Table 6 Consensus photographic scores for the CMC1 joints

\begin{tabular}{|c|c|c|c|c|c|c|}
\hline & \multirow[b]{2}{*}{ Joint } & \multicolumn{4}{|c|}{ Grade } & \\
\hline & & 0 & 1 & 2 & 3 & \\
\hline & & $n$ & $N$ & $n$ & $n$ & Total $n$ \\
\hline \multirow[t]{2}{*}{ All } & CMC1 Right & 261 & 62 & 46 & 11 & 380 \\
\hline & CMC1 Left & 290 & 50 & 29 & 9 & 378 \\
\hline \multicolumn{7}{|c|}{ Males } \\
\hline & CMC1 Right & 127 & 22 & 9 & 0 & 158 \\
\hline & CMC1 Left & 141 & 12 & 4 & 0 & 157 \\
\hline \multicolumn{7}{|c|}{ Females } \\
\hline & CMC1 Right & 134 & 40 & 37 & 11 & 222 \\
\hline & CMC1 Left & 149 & 38 & 25 & 9 & 221 \\
\hline
\end{tabular}

radiography is notable for a higher prevalence of OA in the PIP joints compared with the CMC1 joints and relatively minor gender differences. The other two methods are more similar with a relatively high prevalence of CMC1 HOA in females (comparable to or more prevalent than PIP OA) and low prevalence in males.

All scoring methods showed significant correlations, somewhat stronger in females than in males. To give an indication of a score reflecting degree of involvement, we chose to present a 10 joint aggregate score, choosing the joints that are used in ACR diagnostic criteria (DIP2, DIP3, PIP2, PIP3 and CMC1 on both sides. They are referred to as P10 for the photographic scoring and $\mathrm{R} 10$ and $\mathrm{C} 10$ for radiography and clinical examination respectively). In males the Spearman correlation $\left(R_{s}\right)$ between P10 and R10 was 0.35 (ICC 0.55), for P10 and C10 0.69 (ICC 0.82) and R10 and C10 0.47 (ICC 0.72). Corresponding correlations for females were between P10 and R10: 0.53 (ICC 0.75), for P10 and C10: 0.72 (ICC 0.88) and R10 and C10: 0.66 (ICC 0.83). A three dimensional scatter plot for aggregate 10 joint scores for the three methods is shown in Figure 4.

Table 7 Point prevalence of Hand OA in joint groups by the three methods.

\begin{tabular}{lrrrrrr}
\hline & \multicolumn{3}{c}{ Males (N = 159) } & \multicolumn{4}{c}{ Females (N = 222) } \\
\cline { 2 - 7 } & Total & Right & Left & Total & Right & Left \\
\hline POA of DIPs\% & 48.4 & 39.0 & 32.7 & 50.0 & 45.0 & 34.7 \\
POA of PIPs\% & 36.5 & 28.3 & 20.1 & 27.5 & 22.5 & 12.2 \\
POA of CMC1\% & 5.7 & 5.7 & 2.5 & 25.2 & 21.7 & 15.4 \\
ROA of DIPs\% & 81.8 & 78.0 & 66.7 & 91.9 & 88.3 & 80.6 \\
ROA of PIPs\% & 50.3 & 35.8 & 32.1 & 67.6 & 50.0 & 43.2 \\
ROA of CMC1\% & 25.8 & 18.2 & 19.5 & 35.1 & 27.9 & 28.4 \\
COA of DIPs\% & 69.2 & 61.0 & 53.5 & 75.7 & 68.9 & 59.0 \\
COA of PIPs\% & 28.9 & 20.8 & 18.9 & 22.5 & 18.5 & 14.9 \\
COA of CMC1\% & 13.2 & 7.5 & 10.1 & 36.0 & 26.1 & 26.6 \\
\hline (POA = photography, ROA = radiography, COA clinical examination)
\end{tabular}




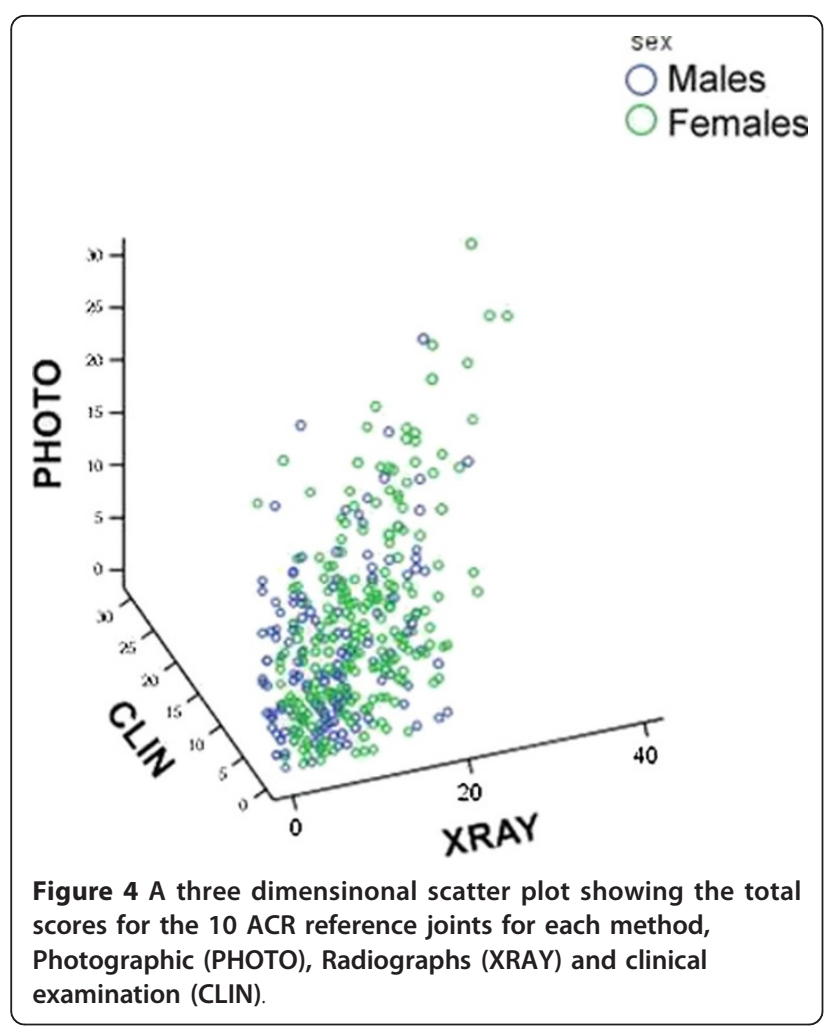

The relationship between the three diagnostic methods and pain

Initially, we started out with three different pain criteria but the question "Hand pain lasting at least one month in the past year" had a low prevalence of positives (Table 1) and we did not find associations with any of the diagnostic methods. The prevalence of ever having hand pain lasting at least one month (the ACR criterion for diagnosis of hand OA) was $20.0 \%$ (10.7\% in males and $27.0 \%$ in females) (Table 1). A positive answer in males was not associated with HOA by any of the methods, but in females there was a modest association with aggregate HOA scores by all three methods (Figure 5).

Sixteen males (10\%) and 92 females (41.4\%) reported "pain sometimes". In males there was no association between OA in DIP and PIP joints and either of the pain criteria. There was however, a significant association between intermittent pain in the $\mathrm{CMC} 1$ joints and HOA severity measured by radiography (OR 7.4 (1.2$46.4), p<0.01$ and clinical examination 14.3 (1.8-112.4), $p<0.001$ ). The number of individuals in this group was low. In females, intermittent pain in individual joints and joint rows was significantly associated with the severity of OA assessed by all three methods (Figure 6).

Further analysis of the associations between intermittent pain in individual joints in females is illustrated in Table 8 , showing odds ratios for the most commonly affected joint in each joint group.

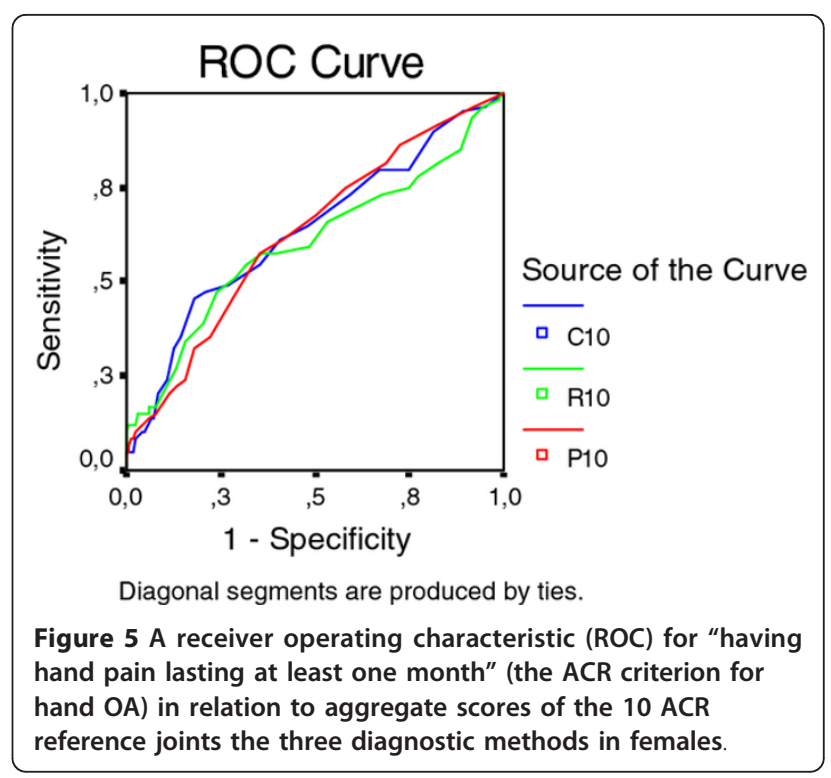

The shortened version of photographic assessment of hand osteoarthritis

In view of the projected use of the photographic method as a screening tool for HOA, particularly in large studies, we constructed a shorter version of the scoring system for practical reasons. In the shorter version (HOASCORE) less attention was paid to the number of affected joints but more on a global assessment in an attempt to describe a trait or disease burden. Thus, the emphasis was on severity in each joint group (DIP, PIP, CMC1) with additional considerations for symmetry and typical joints (ACR 10). Thus, definite nodal OA (score 2 or higher on the reference photographs) on one side, or bilateral suspected OA (scores of 1) were classified as

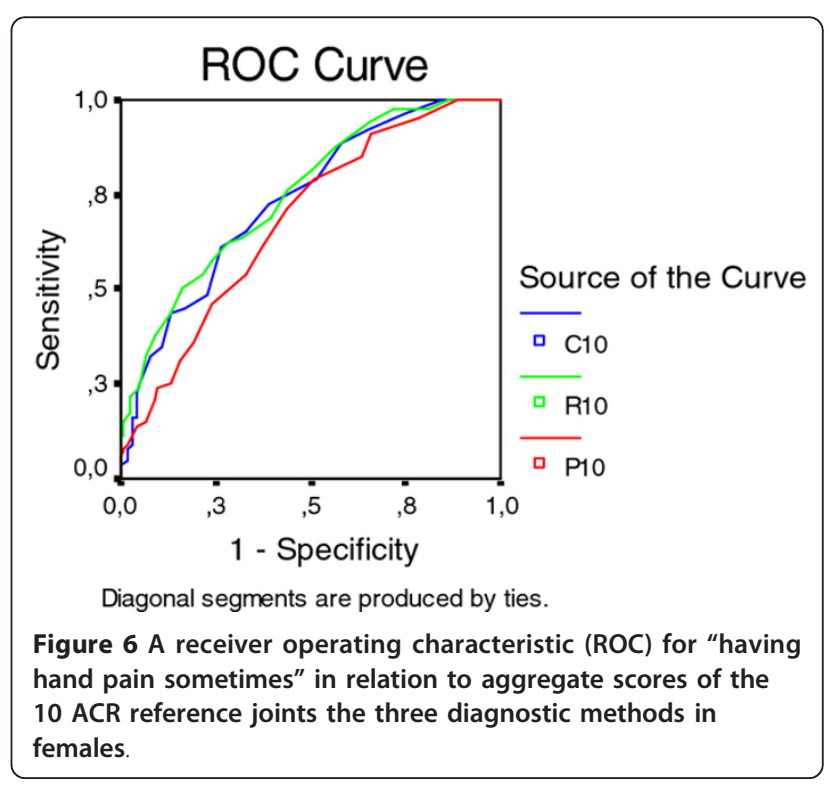


Table 8 Odds ratios for reporting intermittent pain in relation to the presence of osteoarthritis by the three different methods.

\begin{tabular}{|c|c|c|c|c|}
\hline & $\begin{array}{l}\text { Percentage reporting pain } \\
\text { having OA in the joint }\end{array}$ & $\begin{array}{c}\text { Percentage reporting pain } \\
\text { without having OA in the joint }\end{array}$ & Odds ratios and $95 \% \mathrm{Cl}$ & $P$ value \\
\hline \multicolumn{5}{|l|}{ Right DIP2 } \\
\hline Photo & 29.3 & 11.6 & $3.2(1.6-6.4)$ & 0.001 \\
\hline Xray & 21.5 & 4.4 & $5.9(1.4-25.4)$ & 0.008 \\
\hline Clinical examination & 24.0 & 10.2 & $2.8(1.2-6.2)$ & 0.01 \\
\hline \multicolumn{5}{|l|}{ Right PIP3 } \\
\hline Photo & 34.4 & 13.7 & $3.3(1.4-7.6)$ & 0.004 \\
\hline Xray & 27.9 & 11.7 & $2.9(1.4-6.0)$ & 0.003 \\
\hline Clinical examination & 35.7 & 14.1 & $3.4(1.4-8.1)$ & 0.004 \\
\hline \multicolumn{5}{|l|}{ Right CMC1 } \\
\hline Photo & 41.7 & 16.7 & $3.6(1.8-7.2)$ & $<0.0001$ \\
\hline Xray & 51.6 & 10.6 & $9.0(4.4-18.2)$ & $<0.0001$ \\
\hline Clinical examination & 53.4 & 10.5 & $9.8(4.8-20.1)$ & $<0.0001$ \\
\hline
\end{tabular}

Calculations for the most commonly affected joints in each joint group are shown. (right DIP2, right PIP3 and right CMC1)

1 (some evidence of HOA). Bilateral definite nodal OA was required for a score of 2 (definite HOA) and bilateral definite OA plus one or more severely affected joints were required for a global score of 3 (severe HOA) at each site. Adding the scores for the three joint groups resulted in an aggregate score of 0-9, subsequently truncated to zero to four or more $(4+)$. An example of the use of the shortened version is shown in Figure 7. The scores obtained with the shortened version were highly correlated with the joint for joint scores for photography (P10) $\left(\mathrm{R}_{\mathrm{s}}\right.$ 0.82) and also had reasonably good correlations with radiography (R10) $\left(R_{s}\right.$ $0.56)$ and clinical examination $(C 10)\left(R_{s} 0.70\right)$. This is further illustrated in Figure 8.

This shortened version was subsequently applied for scoring the whole AGES-Reykjavik cohort ( $\mathrm{n}=5170)$. The prevalences of photographic HOA by this method (results for the AGES Reykjavik cohort in parestheses) were $0($ No HOA $)=30.3 \%$ (31.2), 1 (some evidence of $\mathrm{HOA})=23.1 \%$ (22.6), 2 (definite mild HOA) $=20.7 \%$ (19.7), 3 (definite moderate HOA) $=13.8 \%(13.5)$ and 4 $+($ severe $\mathrm{HOA})=12.0 \%(13.0)$.

\section{Discussion}

This paper describes the use of high quality digital hand photographs for the diagnosis and severity grading of hand osteoarthritis. The study population was a random sample of 381 elderly (mean age 76 ) participants in the AGES-Reykjavik Study who also had standard hand radiographs and expert clinical hand examination in addition to the digital photographs.

In the first step of the study, we developed a set of reference photographs to facilitate the reading and grading of the hand photographs. These were chosen after repeated assessments. By the help of these reference photographs, we managed to achieve an interobserver agreement measured by ICC which is comparable to that reported in radiological studies [24-26].

In the second phase of the study, we compared hand photographs with the results of radiography and clinical examination in the same group of individuals with regard to the diagnosis of $\mathrm{HOA}$, and the grading of HOA severity. Unfortunately, the definition of HOA is very problematic because of lack of an absolute clinical, radiological, or pathological standard that the epidemiology of hand OA can be compared with. The ACR criteria for clinical diagnosis of HOA [27] are useful for identifying HOA patients with persistent symptoms but the prevalence of HOA by those criteria is low. A study of an elderly population in Iceland based on the ACR criteria [13] found that the prevalence of symptomatic hand OA was $3 \%$ in men and $7 \%$ in women. The symptoms criterion, however, showed considerable variation with time and thus the symptomatic OA group was not stable.

Radiological changes are most commonly used to grade hand OA. At present, several different radiographic classification systems are used but the KellgrenLawrence (K-L) scale for grading of radiological changes has been most widely used in the past [17]. In a review by Marshall and colleagues in 2008 it was reported that in 1996-2005 thirty epidemiological studies, all using the $\mathrm{K}-\mathrm{L}$ scale, used 13 different cut-off points for diagnosis of systemic HOA [28]. The prevalence of symptomatic HOA is also low using the radiographic criteria, in the Framingham Study it had a point prevalence of $1.8-5.5 \%$ [29].

In the present study, we found several differences between the three methods. Radiography was more sensitive than either of the other methods when the cut-off 


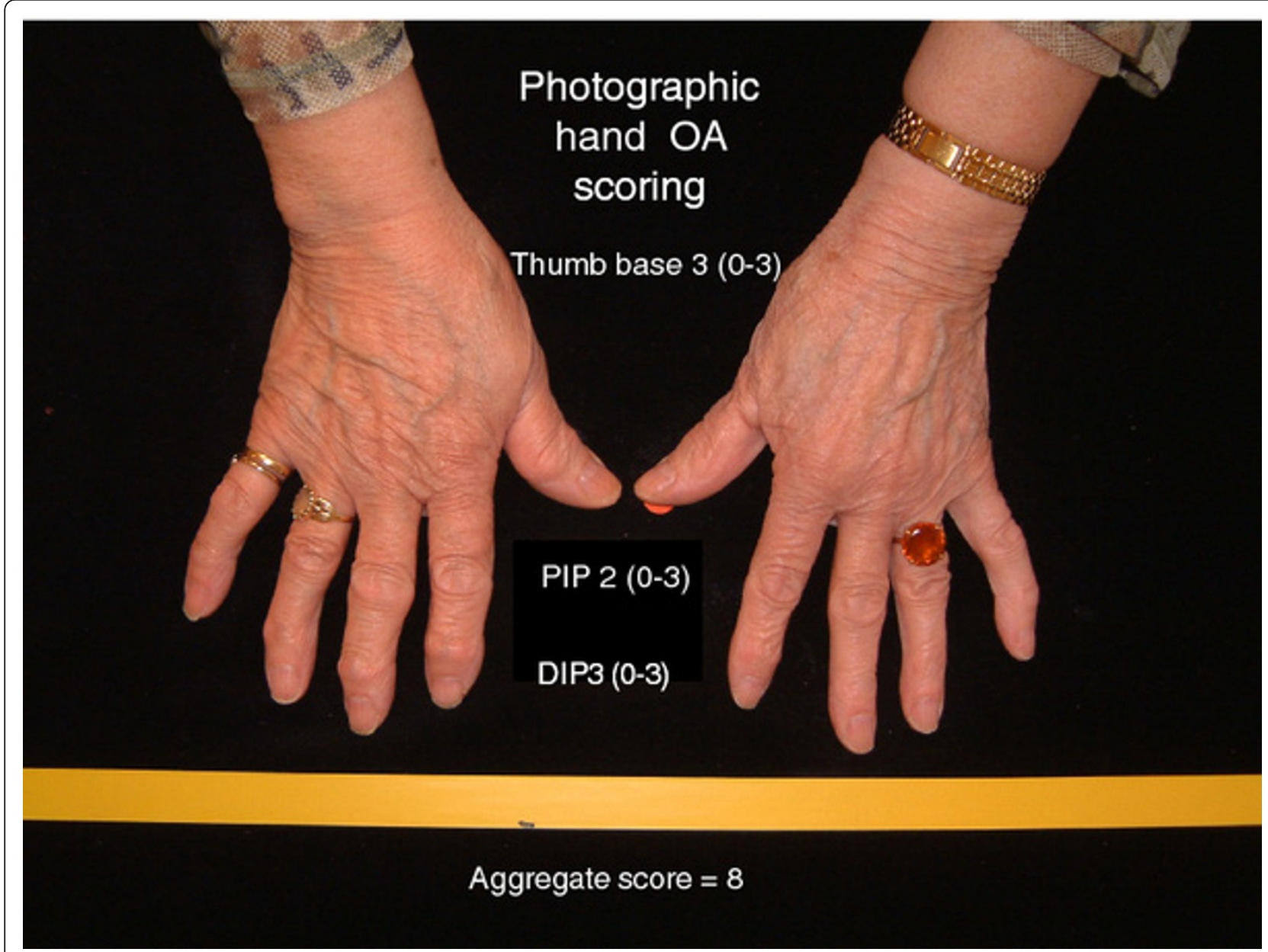

Figure 7 An example of the use of the abbreviated photographic scoring system for hand OA. Aggregate scores of $\geq 4$ were assigned a score of 4 , the most severe grading (HOASCORE).

was set at $\mathrm{K}-\mathrm{L} \geq 2$. Radiography also had a higher relative prevalence in the PIP joints than the other methods. Aggregate scores for all methods showed highly significant correlations and with few exceptions, they tended to identify the same individuals as having severe HOA. Not unexpectedly, photographs and clinical examination results were more closely correlated to each other than to radiography. There were a few individuals with high radiography scores and low photographic and clinical scores (non-nodal hand osteoarthritis), which may constitute a relevant subset of $\mathrm{HOA}$ and will be the subject of further studies. Agreement between the three methods was considerably better in females than males. Weight and BMI were negatively associated with photographic HOA scores but despite reports indicating a positive association between radiographic $\mathrm{HOA}$ and weight we found no such association [30]. The photographic finding is not entirely unexpected and probably related to increased finger soft tissues hindering the detection of nodes and deformities.
Pain is the central symptom of $\mathrm{OA}$ and in the next phase of the study, we investigated the relationship between pain and HOA detected by the three methods.

Somewhat surprisingly, we found no association between HOA and pain in males except in those with CMC1 OA who admitted to pain in that joint. This could be related to the high age of our participants but some previous studies have reported a weaker association between radiographic HOA and pain in males than females [31,32]. In females, we found only a modest similar association between "pain in hands lasting at least one month" and aggregate severity scores for all three methods. The prevalence of this symptom and the weak association are in analogy with that found in previous studies [7]. Intermittent pain (pain sometimes) was more strongly related to HOA findings, both aggregate HOA scores and pain in individual joints. All three methods performed similarly in the case of the DIP joints, but radiography showed a somewhat stronger association with pain than photography for PIP and 

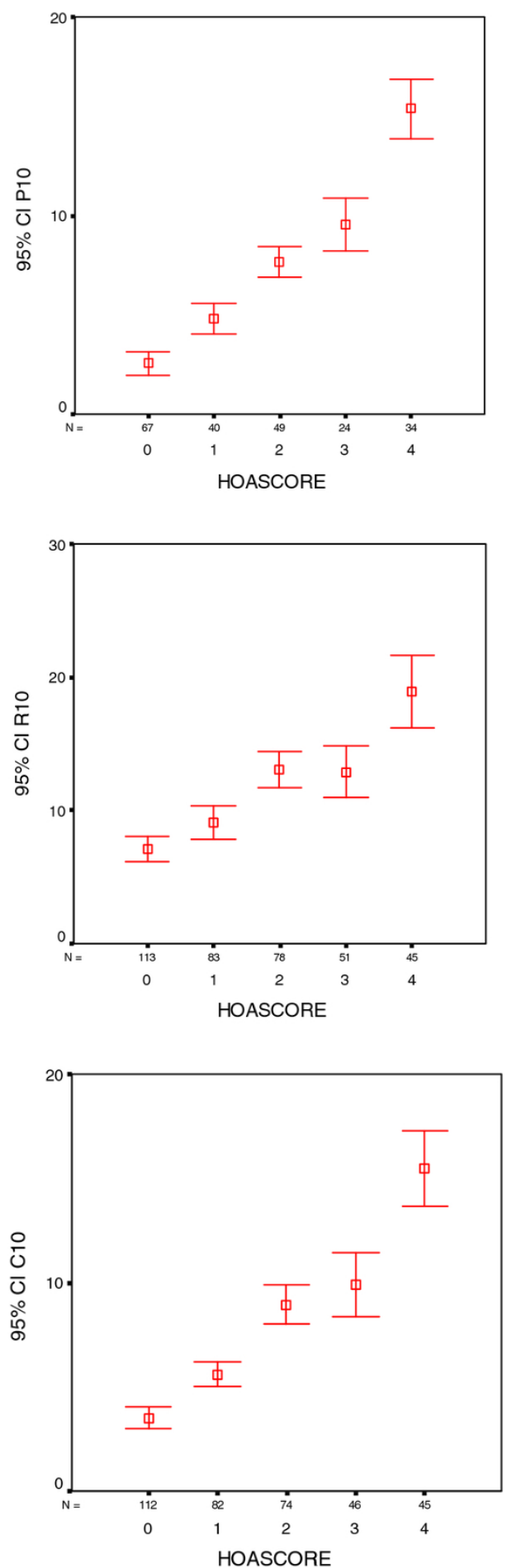

Figure 8 Error bars (mean, 95\% confidence interval) showing the relation between the three diagnostic methods and the shortened version of the photographic assessment (HOASCORE). P10 (Photographic), R10 (Radiographic) and C10 (clinical examination) stand for aggregate scores for the $10 \mathrm{ACR}$ reference joints.
CMC1 joints. For the PIP joints, radiography also appeared superior to clinical examination.

In the final step of the study plan, we developed a shortened version of the photographic system. If information about HOA severity could be collected from some of the large detailed studies like the AGES-Reykjavik Study, it would open up a number of possibilities to examine the relationship of HOA to lifestyle and all kinds of conditions. If we consider HOA severity as a continous trait, the exact prevalences are less important than information the relative burden of HOA in each individual.

Using photographs for diagnosing HOA has a number of advantages. The method is simple, inexpensive, and involves little discomfort and no radiation. This study shows that the taking and the reading of the photographs can be standardized in a reproducible fashion with adequate inter- and intraobserver variation, at least in this age group. The photographic method in this age group is also in many ways comparable to the other methods, identifying mainly the same patients and showing comparable or only slightly inferior association with symptoms. Compared with clinical examination it also has the advantage of having an image for later analysis. The shortened version (HOASCORE) has practical advantages, speeding up the reading and appears to be particularly suitable for analysis of very large studies such as the AGES-Reykjavik Study where information about HOA status can be analysed in relation to the extensive health-related information available on each participant. By applying the HOASCORE to the AGESReykjavik Study population, we have discovered a number of potentially important new systemic associations, undetectable except in large studies $[4,21,33]$.

The disadvantages of photography is that it is less sensitive on joint for joint analysis than either radiography and clinical examination particularly on PIP and CMC1 analysis. Also, compared with radiography it reflects anatomy less well. Bone damage or repair cannot be evaluated and the method cannot be used to diagnose erosive OA. The photographic scores also negatively associated with individual weight suggesting lower sensitivity in heavy subjects. Finally, a recent study suggests that photographic scoring of HOA is relatively insensitive to change, at least in this age group [34].

Of course, our conclusions regarding the use of photographs to diagnose HOA are limited to the current age group. In many ways this is a suitable age group to examine since it reflects cumulative disease burden and organ damage aquired over a long time. There is no reason to believe that photography performs differently in other age groups. In the future, it is even possible that photographs will prove to be more sensitive than 
radiographs in younger subjects with early disease who have nodal HOA but have not had time to develop radiological changes.

\section{Conclusions}

High quality hand photographs can be used to diagnose and grade hand osteoarthritis in the elderly. The method has the advantage of being inexpensive and easy to perform. By using a slightly simplified method of reading, it appears to be highly suitable for use in large studies.

\section{Abbreviations}

ACR: American College of Rheumatology; BMl: Body Mass Index; MRI: Magnetic Resonance Imaging; CMC1: First carpometacarpal (thumb base) joint C10: Clinical hand osteoarthritis severity score for 10 joints (DIP2: DIP3: PIP2:PIP3 and CMC1 on both sides; DIP: Distal interphalangeal joint; HOA: Hand osteoarthritis; ICC: Average Measure Intraclass correlation coefficient; KL: Kellgren-Lawrence scoring system; OA: Osteoarthritis; P10: Photographic hand osteoarthritis severity score for 10 joints (DIP2: DIP3: PIP2: PIP3 and CMC1 on both sides; PIP: Proximal interphalangeal joint; R10: Radiographic hand osteoarthritis severity score for 10 joints (DIP2: DIP3: PIP2: PIP3 and CMC1 on both sides; GOA: Generalized osteoarthritis; GPH: Guðrún P. Helgadóttir; HJ: Helgi Jonsson.

\section{Acknowledgements}

Age, Gene/Environment Susceptibility Reykjavik Study (AGES-

Reykjavik) has been funded by NIH contract N01-AG-12100, the NIA Intramural Research Program, Hjartavernd (the Icelandic Heart Association), and the Althingi (the Icelandic Parliament), the Icelandic Osteoarthritis Fund and the University of Iceland Research Fund. The study is approved by the Icelandic National Bioethics Committee, (VSN: 00-063) and the Data Protection Authority. The researchers are indebted to the participants for their willingness to participate in the study.

\section{Author details}

${ }^{1}$ Landspitalinn University Hospital, University of Iceland, IS-108 Fossvogur, Reykjavik, ICELAND. ${ }^{2}$ University of Iceland, Reykjavik, ICELAND. ${ }^{3}$ Icelandic Heart Association, University of Iceland, Reykjavik, ICELAND. ${ }^{4}$ Icelandic Heart Association, Kopavogur, ICELAND. ${ }^{5}$ Roentgen Domus Medica, Reykjavik, ICELAND. ${ }^{6}$ Akureyri Central Hospital, Akureyri, ICELAND. ${ }^{7}$ National Institute on Aging, Bethesda, MD, USA.

\section{Authors' contributions}

HJ, Main author. GPH, Data acquisition, Manuscript preparation. TA, Statistical analysis, Manuscript preparation. JES, Data acquisition, Critical reading of manuscript. GE, Project management, Critical reading of manuscript. SS, Data acquisition, Critical reading of manuscript. GJE, Data acquisition, Critical reading of manuscript. AJ, Data acquisition, Critical reading of manuscript. $\mathrm{TI}$, Data acquisition, Critical reading of manuscript. TBH, Project management, Manuscript preparation. $L L$, Project management, Critical reading of manuscript. VG, Project management, Manuscript preparation. All authors read and approved the final manuscript.

\section{Competing interests}

The authors declare that they have no competing interests.

Received: 14 October 2011 Accepted: 16 February 2012 Published: 16 February 2012

\section{References}

1. Jones G, Cooley HM, Bellamy N: A cross-sectional study of the association between Heberden's nodes, radiographic osteoarthritis of the hands, grip strength, disability and pain. Osteoarthr Cartil 2001, 9(7):606-611.

2. Fautrel $B$, Hilliquin P, Rozenberg S, Allaert FA, Coste P, Leclerc A, Rossignol M: Impact of osteoarthritis: results of a nationwide survey of 10.000 patients consulting for OA. Joint Bone Spine 2005, 72(3):235-240.
3. Zhang Y, Niu J, Kelly-Hayes M, Chaisson CE, Aliabadi P, Felson DT: Prevalence of symptomatic hand osteoarthritis and its impact on functional status among the elderly: The Framingham Study. Am J Epidemio/ 2002, 156(11):1021-1027.

4. Jonsson $H$, Helgadottir GP, Aspelund T, Eiriksdottir G, Sigurdsson S, Siggeirsdottir K, Ingvarsson T, Harris TB, Launer L, Gudnason VG: Hand osteoarthritis severity and severe hip OA are associated with total knee joint replacement independently of BMI. The AGES-Reykjavik Study. Open Rheumatol J 2011, 5:7-12.

5. Cooper C, Egger P, Coggon D, Hart DJ, Masud T, Cicuttini F: Generalized osteoarthritis in women: pattern of joint involvement and approaches to definition for epidemiological studies. J Rheumatol 1996, 23:1938-1942.

6. Vignon E: Hand osteoarthritis and generalized osteoarthritis: a need for clarification. Osteoarthr Cartil 2000, 8:(Suppl A):22-24.

7. Dahaghin S, Bierma-Zeinstra SM, Ginai AZ, Pols HA, Hazes JM, Koes BW: Prevalence and pattern of radiographic hand osteoarthritis and association with pain and disability (the Rotterdam study). Ann Rheum Dis 2005, 64(5):682-687.

8. Botha-Scheepers S, Riyazi N, Watt I, Rosendaal FR, Slagboom E, Bellamy N Breedveld FC, Kloppenburg M: Progression of hand osteoarthritis over 2 years: a clinical and radiological follow-up study. Ann Rheum Dis 2009, 68(8):1260-1264, Epub 2008 Aug 26.

9. Acheson RM, Collart AB, Greenberg RH, Clemett AR: New Haven survey of joint disease Photographs and other variables in screening for arthritis of the hands. Am J Epidemiol 1969, 90(3):224-235.

10. Stern AG, Moxley G, Sudha Rao TP, Disler D, McDowell C, Park M, Schumacher HR: Utility of digital photographs of the hand for assessing the presence of hand osteoarthritis. Osteoarthr Cartil 2004, 12(5):360-365.

11. Hirsch R, Guralnik JM, Ling SM, Fried LP, Hochberg MC: The patterns and prevalence of hand osteoarthritis in a population of disabled older women: The Women's Health and Aging Study. Osteoarthr Cartil 2000, 8 (Suppl A):16-21.

12. Felson DT, Lawrence RC, Dieppe PA, Hirsch R, Helmick CG, Jordan JM, Kington RS, Lane NE, Nevitt MC, Zhang Y, Sowers M, McAlindon T, Spector TD, Poole AR, Yanovski SZ, Ateshian G, Sharma L, Buckwalter JA, Brandt KD, Fries JF: Osteoarthritis: New insights part 1: The disease and its risk factors. Ann Intern Med 2000, 133(8):635-646.

13. Aspelund $G$, Gunnarsdottir S, Jonsson P, Jonsson H: Hand osteoarthritis in the elderly. Application of clinical criteria. Scand J Rheumatol 1996, 25(1):34-36

14. Jonsson $\mathrm{H}$, Eliasson GJ, Petursson E: Scintigraphic hand osteoarthritis (OA) - prevalence, joint distribution and association with OA at other sites. J Rheumatol 1999, 26:1550-1556.

15. Eliasson GJ, Bjorgvinsson $\mathrm{E}$, Jonsson $\mathrm{H}$ : Magnetic resonance imaging of the thumb base in severe symptomatic osteoarthritis; a comparison with radiographs and clinical symptoms. Open Arthritis J 2009, 2:1-6.

16. Eliasson GJ, Bragason AO, Bjorgvinsson $E$, Jonsson H: Low level laser therapy (LLLT) of the osteoarthritic CMC1 joint. Report of six patients using magnetic resonance imaging (MRI) to monitor changes after treatment. Scand J Rheumatol 2006, 35:(Suppl 121):50.

17. Kellgren JH, Lawrence JS: Radiological assessment of osteo-arthrosis. Ann Rheum Dis 1957, 16(4):494-502.

18. Verbruggen G, Veys EM: Numerical scoring systems for the evolution of osteoarthritis of the finger joints. Arthritis Rheum 1996, 39:308-320.

19. Jonsson H, Eliasson GJ, Jonsson A, Eiriksdottir G, Sigurdsson S, Aspelund T, Harris TB, Gudnason V: High hand joint mobility is associated with radiological CMC1 osteoarthritis: the AGES-Reykjavik study. Osteoarthr Cartil 2009, 17(5):592-595.

20. Eliasson GJ, Verbruggen G, Stefansson SE, Ingvarsson T, Jonsson H: Hand radiology characteristics of patients carrying the T303M mutation in the gene for matrilin-3. Scand J Rheumatol 2006, 35:138-142.

21. Jonsson $H$, Helgadottir GP, Aspelund T, Eiriksdottir G, Sigurdsson S, Ingvarsson T, Harris TB, Launer L, Gudnason V: Hand osteoarthritis in older women is associated with carotid and coronary atherosclerosis: the AGES Reykjavik study. Ann Rheum Dis 2009, 68(11):1696-1700.

22. Kornaat PR, Sharma R, van der Geest RJ, Lamb HJ, Kloppenburg M, le Graverand MP, Hellio, Bloem $J$, Watt I: Positive association between increased popliteal artery vessel wall thickness and generalized osteoarthritis: is OA also part of the metabolic syndrome? Skeletal Radiol 2009, 38:1147-1151. 
23. Harris $T B$, Launer $L$, Eiriksdottir $G$, Kjartansson $O$, Jonsson PV, Sigurdsson G, Thorgeirsson G, Aspelund T, Garcia ME, Cotch MF, Hoffman HJ, Gudnason V: Age, Gene/Environment Susceptibility-Reykjavik Study: multidisciplinary applied phenomics. Am J Epidemiol 2007, 165(9):1076-1087.

24. Clohisy JC, Carlisle JC, Trousdale R, Kim YJ, Beaule PE, Morgan P, StegerMay K, Schoenecker PL, Millis M: Radiographic evaluation of the hip has limited reliability. Clin Orthop Relat Res 2009, 467(3):666-675.

25. Lane NE, Nevitt MC, Genant HK, Hochberg MC: Reliability of new indices of radiographic osteoarthritis of the hand and hip and lumbar disc degeneration. J Rheumatol 1993, 20(11):1911-1918.

26. Scott WWJ, Lethbridge-Cejku M, Reichle R, Wigley FM, Tobin JD, Hochberg MC: Reliability of Grading Scales for Individual Radiographic Features of Osteoarthritis of the Knee: The Baltimore Longitudinal Study of Aging Atlas of Knee Osteoarthritis. Invest Radiol 1993, 28(6):501.

27. Altman R, Alarcon G, Appelrouth D, Bloch D, Borenstein D, Brandt K Brown C, Cooke TD, Daniel W, Gray R, et al: The American College of Rheumatology criteria for the classification and reporting of osteoarthritis of the hand. Arthritis Rheum 1990, 33(11):1601-1610.

28. Marshall M, Dziedzic KS, van der Windt DA, Hay EM: A systematic search and narrative review of radiographic definitions of hand osteoarthritis in population-based studies. Osteoarthr Cartil 2008, 16(2):219-226.

29. Niu J, Zhang Y, LaValley M, Chaisson CE, Aliabadi P, Felson DT: Symmetry and clustering of symptomatic hand osteoarthritis in elderly men and women: the Framingham Study. Rheumatol (Oxford) 2003, 42(2):343-348.

30. Yusuf E, Nelissen RG, loan-Facsinay A, Stojanovic-Susulic V, DeGroot J, van Osch G, Middeldorp S, Huizinga TW, Kloppenburg M: Association between weight or body mass index and hand osteoarthritis: a systematic review. Ann Rheum Dis 2010, 69:761-765.

31. Lawrence JS, Bremner JM, Bier F: Osteo-arthrosis. Prevalence in the population and relationship between symptoms and x-ray changes. Ann Rheum Dis 1966, 25(1):1-24.

32. Dahaghin S, Bierma-Zeinstra SM, Hazes JM, Koes BW: Clinical burden of radiographic hand osteoarthritis: a systematic appraisal. Arthritis Rheum 2006, 55(4):636-647.

33. Jonsson $H$, Helgadottir GP, Aspelund T, Eiriksdottir G, Sigurdsson $S$, Siggeirsdottir K, Ingvarsson T, Harris TB, Launer L, Gudnason V: The presence of total knee or hip replacements due to $O A$ enhances the positive association between hand $\mathrm{OA}$ and atherosclerosis in females: The AGES-Reykjavik Study. Ann Rheum Dis 2011.

34. Jonsson $\mathrm{H}$, Helgadottir GP, Sverrisdottir JE, Eiriksdottir G, Sigurdsson $\mathrm{S}$, Siggeirsdottir S, Ingvarsson T, Harris TB, Launer L, Gudnason V: Photographic scoring is insensitive for monitoring progress of hand osteoarthritis, but side by side comparison of photographs detects progress at 5 year intervals in the elderely. The AGES-Reykjavik Study. Osteoarthr Cartil 2010, 18(Suppl 2):183.

\section{Pre-publication history}

The pre-publication history for this paper can be accessed here: http://www.biomedcentral.com/1471-2474/13/20/prepub

doi:10.1186/1471-2474-13-20

Cite this article as: Jonsson et al:: The use of digital photographs for the diagnosis of hand osteoarthritis: the AGES-Reykjavik study. BMC

Musculoskeletal Disorders 2012 13:20.

\section{Submit your next manuscript to BioMed Central and take full advantage of:}

- Convenient online submission

- Thorough peer review

- No space constraints or color figure charges

- Immediate publication on acceptance

- Inclusion in PubMed, CAS, Scopus and Google Scholar

- Research which is freely available for redistribution 